\title{
Introduction the Ninth Annual Lecture
}

\author{
by Louis Eeckhoudt*
}

Economists who teach applications of risk theory to students in micro-economics or finance face a dilemna that is not always easy to resolve. Indeed they start the course by emphasizing that risk is everywhere present in economic life and should be appropriately taken into consideration. Then, as time passes, they describe and analyze a great variety of risk reducing instruments such as insurance, option markets, diversification and so on. As these tools are rather efficient, it turns out that in economic life, risk is important but also to a wide extent controllable. Consequently, its real importance is dampened.

It appears that the risks faced in the medical activity are allogether more acute than in the economic sphere. Of course, the uncertainty attached to the monetary consequences of health related events can be reduced through private or public insurance mechanisms. However the consequences of a more "personal" nature (pain, distress, morbidity, or mortality ...) are neither diversifiable nor insurable. As a result risk is eminently present for the patient and his physician and the only very partial way to reduce its impact is to search for information. In the medical field, this activity takes the form of diagnostic tests.

As medical decisions imply that risks will have to be assumed, they represent of course an extremely important field of application for decision theory. Besides, society as a whole has to pay for the consequences of decisions taken at the individual level and this explains why health problems raise a sometimes hot political debate. Anyway, in a period of scarcity it becomes crucial to supply medical services in a cost effective manner. Under these circumstances it is quite fortunate that the Geneva Association has decided to devote one of its annual lectures to the analysis of decisions in the medical field.

In order to get an excellent lecture, one needs two complementary inputs: an interesting topics and a very good speaker. In this respect we are extremely happy that Professor Milton WEINSTEIN from the Harvard School of Public Health has accepted to deliver this lecture.

Professor Weinstein is a pure product from Harvard University where he got a B.A. in Applied Mathematics and a Ph.D. from the Kennedy School of Government. He then got appointed to the School of Public Health where he developed applications of risk theory to the analysis of medical decisions. His curriculum vitae reveals a rather distinctive feature: M. Weinstein published important articles both in economic and medical journals so that he is

\footnotetext{
* Professor of Economics at the Catholic Faculties of Mons and Lille.
} 
well known in these two professions. While very active in the school of Public Health, M. Weinstein was also a founding member of the "Society for Medical Decision Making" of which he is now President. This Society aims at promoting fundamental and empirical research at the interface between medicine, economics and decision sciences. The Society is now well-established in the U.S. and it is expanding in Western Europe.

I am thus quite confident that M. Weinstein will give us a clear, complete and stimulating survey of recent developments in a very promising sector of research activity. As far as I can see, such a research can be very productive on various accounts. First, much insight can be gained from a comparison between the individual behavior in the face of purely monetary risks and that observed in the presence of "physical" uncertainties. Secondly the kind of research that will be suveyed here has the advantage of leading rather easily to "realworld" applications which can have a significant impact both at the individual and community levels. Finally, it is rather obvious that the cost-effective use of medical services is not a matter of indifference for the insurance industry or a system of social security. As a result the topics of medical decision making under uncertainty seems to perfectly fit the purposes of the Geneva Association. For all these reasons it is thus a very great pleasure and also an honour to welcome here the Geneva Association, Milton Weinstein and the discussants. 